\title{
Influence of Socioeconomic Factors on Utilization of Research Findings among the Fisher Folks in Kisumu Municipality, Kenya
}

\author{
Onyango G.O ${ }^{1}$, Dr. Bosire. $E^{2}$, Dr Akala. B ${ }^{3}$. Prof Otieno W.A ${ }^{4}$ \\ ${ }^{1}$ (Department of Environmental science, School of Environment and Earth Sciences, Maseno University Kenya) \\ ${ }^{2}$ (Department of Environmental science, School of Environment and Earth Sciences, Maseno University Kenya) \\ ${ }^{3}$ (Department of Environmental science, School of Environment and Earth Sciences, Maseno University Kenya) \\ ${ }^{4}$ (Restech Maseno Kisumu, Maseno University Kenya)
}

\begin{abstract}
The purpose of this study was to investigate influence of socio-economic factors on utilization of research findings in the management of Environment and Fishing Efforts in Kisumu Municipality kenya. The objectives of this study was to determine influence of socioeconomic factors on utilization of research findings and innovation. Cross sectional descriptive survey design was used in this study. Households were the unit of analysis. From a study population of 15,179 households, a minium sample of 384 household heads were used, proportionate sampling and systematic sampling were used to select households according to location of study area. Purposive sampling were also used to get key informants. Primary data was collected through questionnaires, key informant interviews, Focus Group Discussions, field observation, and photography. The quantitative data were analyzed using descriptive statistics to establish relationships. Qualitative data were analyzed by creating patterns and themes. Logistic regression analysis were used to establish influence of socio economic factors on fishing effort to answer the research questions. The regression output shows relationship between fishfolks socioeconomic status and utilization of research findings was positive $r=0.320, R^{2}=0.102$ of the variation and $\beta=0.320, p<0.05$ shows that social economic status significantly influence utilization of research findings. The study concluded that there is a relationship between social economic activities and utilization of research findings. It was recommended that the Kisumu Municipality/County Government should take a deliberate step to reduce poverty levels by creating a conducive alternative investment opportunies to reduce over dependancy on the lake as source of employment.
\end{abstract}

Key Words: Socio economics, Utilization, Research Findings, Fisher folks

\section{Introduction}

Globally, the natural environment has been threatened by the human activities which involve extraction of its resources and pollution. This has affected both the terrestrial and aquatic environment which support organisms, to some extend biodiversity are threatened. The Lakes, Reservoirs and Rivers are among the most extensively altered ecosystem on the earth. Transformation include changes in morphology of Rivers and Lakes, Hydrology, Biogeochemistry of Nutrients and toxic substance, ecosystem metabolism and storage carbon, loss of native species, expansion of invasive species and disease emergences (Stephen et al., 2011). The key drivers of this threat to the global environment are (a) population growth (b) pollution of our natural environment (c) climate change and (d) over exploitation of our renewable and non-renewable resources (David et al., 2006). Much remains to be done to engage the global citizens to reverse this threat to our environment through dissemination/ utilization of research findings or doing further research on how to create awareness on degradation of environment to reverse the process.

Population growth has been the main driver in environmental degradation/modification, at the moment it has become difficult to understand and predict how environmental changes will interact since many parts of the earth have been polluted in one way or the other (Novine et al., 2010). In Asia which has been experiencing high population growth which has also come with its own demands and challenges. Among the demand and challenges are demand for more fire wood, more Agricultural land to grow more food, increase sanitation challenges due to increase of more informal settlements and processing of waste generated has been a problem. Apart from this, more nutrient enrichment of water bodies has been taking place from untreated sewage discharge, and erosion of nitrogen fertilizers which are used in Agricultural activities. In China particularly, $47 \%$ of the wet lands are manmade composed of rice paddy and fish ponds (Wolfgang et al., 2013). This has led to Algae bloom in the water bodies which is a health risk to the surrounding population. The question is, are the people of China aware of this emerging challenges of environmental degradation and what are they doing to address it? Probable various research done on environmental issues are not reaching the people to use them to address these challenges. A similar situation is taking place right here in Kenya particularly Lake Victoria 
Kenya where serious degradation of environment is taking place, just like China the public need to be involved and educated to conserve the environment to reverse this trend.

In South America which covers an area of 17.8 million $\mathrm{km}^{2}$ environmental degradation is still a big problem, the population of the continent has been growing very fast and currently stands at 381 million people. The end result has been environmental degradation where more and more waste products are not being managed properly and nutrient enrichment is taking place in water points resulting in Algae bloom (Wolfgang et al., 2013). This is particularly experienced in Brazil which is a good example where there has been growth of Agroindustries and urbanization which has resulted in discharge of waste water without treatment into rivers and water reservoirs. The occurrence of toxic cyanobacterial bloom has been registered in 11 out of 26 Brazilian states from North to South. These blooms occur mainly in reservoirs but there are records of occurrence in several coastal lagoons, natural lakes, rivers and estuaries. In general, there is little information about cyanotoxin analysis or toxicity test done with cyanobacteria bloom material. The consequences of toxic cyanobacteria bloom occurrence are underestimated or undiscovered by different authorities responsible for the environment and water quality control, the management actions, preventive plans and remedial measures are usually only implemented when a serious event occurs. It is common to observe that these actions are restricted to a few weeks surrounding the event, depending on the media attention for the case (Ingrid, 2005). In Brazil just like China very little is done to address the degradation going on and probably due to lack of access and awareness of research findings which have been generated to reverse the process. In this case lack of dissemination of environmental research findings has led to low awareness of effects of environmental degradation and its impact to the environment and population health and this need to be addressed. A similar situation of what is happening in Brazil is happening in Lake Victoria Kenya and this formed the basis of this research; to find out why research information generated has not been disseminated /utilized to conserve the environment.

Lake Victoria is the second largest fresh water Lake in the world with surface area of $68,000 \mathrm{~km}^{2}$ (Linda et al., 2003) and it is shared by three East African countries namely Kenya, Uganda and Tanzania. Kenya occupy $6 \%$ of water mass, Uganda occupy $43 \%$ of water mass and Tanzania which has the largest share of 51 $\%$ of water mass (Regional Frame survey Report, 2012). The Lake has a catchment area of 193,000km ${ }^{2}(\mathrm{Uganda}$ $30,880 \mathrm{~km}^{2}, 16 \%$; Kenya 42,460km², 22\%; Tanzania 84,920km²,44\%; Rwanda 21,120 km², $11 \%$; Burundi $13,510 \mathrm{~km}^{2}, 11 \%$ ) with a rapidly growing population of over 35 million people World Bank, (2009). The Lake is relatively shallow with a maximum depth of $69 \mathrm{~m}$ (Johnson et al., 2000). The implication of high population growth is more of socioeconomic activities which is degrading this ecosystem due to high demand of the environmental resources which is a source of livelihood. As a result of this degradation taking place more dissemination and utilization of environmental and fisheries research findings is needed to utilize this resource in a sustainable way.

Globally an enormous amount of information and data has already been generated, and will continue to be generated in physical, chemical and biological aspects such as limnology, hydrology, climatology, ecology, biochemistry and many more, all of which contribute to a better understanding of the state of the lakes, reservoirs and other lentic water bodies. There is also a growing number of studies on the managerial aspect of aquatic, terrestrial and riparian ecosystems including water quality, sediment quality, shoreline environment, inflowing and outflowing water systems extending to upper watershed tributaries. A needed component not yet produced is a means of compiling and utilising holistically, practically-synthesized information and data on such thematic and disciplined subjects (Research centre for sustainability and environment, Shiga University and International lake Environment committee Foundation, 2014). In Kenya the quantity of data and research on Lake Victoria and its drainage is overwhelming. The number of research done to generate knowledge is estimated at about 405 (LVBC Knowledge management Portal, 2013). The key thematic areas which have been researched on are aquatic plants, parasites of fish, different species of fish, water budget, invertebrates, human socio-economic activities, pollutants discharged in Lake Victoria and climate change effect on Lake Victoria Basin (LVB), just to mention a few. These environmental and fisheries research findings are important to the people living and working within the Lake Victoria Basin depending on their socio-economic activities. Out of 405 environmental research findings, it is interesting to note that 9 has been done to address the subject of how best the research information generated could be utilized in solving the emerging environmental degradations and fisheries problems. This suggests low adoption of research findings hence this needed to be examine on factors that influence their adoption.

Despite all these environmental and fisheries research findings done so far, ecosystem health degradation is still a threat in Lake Victoria and its Basin. The major challenge might be lack of access and awareness for utilization since most of the findings are published in international journals not accessible by fisher folks. The other problem might be lack of Resource Centre where various researches conducted can be stored for easy access to create awareness for utilization by fisher folks or may be a problem exists on how the research findings are disseminated to fisher folks or may be dissemiation does not exist at all. This dissemiation 
helps to create an informed society which is a prerequisite to conservation efforts (Ogutu-Ohwayo et al., 2006). After considering the availability of environmental and fisheries research finding, it would appear that further research may not be the main priority but rather dissemination and utilization of existing information for sustainable management of LVB resources. Therefore, despite the growing interest in the concept of utilization of environmental and fisheries research findings for sustainable management of LVB. There remains important knowledge gaps on socioeconomic factors on one hand and utilization of environmental research findings generated and fishing effort on the other hand which calls for further research.

\subsection{Statement of the Problem}

Despite many studies having been done around LVB on water quality, policies, conservation issues and challenges, climate change, water budget, fishing gears and cultural issues of communities, little attention has been given on how well the environmental and fisheries research findings can be disseminated to create awareness for utilization to conserve lakes's resource among the fisher folks. The challenges facing the lake are still persisting and getting worse. There is not much information available which address how best the environmental and fisheries research findings can be disseminated and utilized to address the current challenges facing the LVB. Lake Victoria is an important ecosystem within LVB because it support a variety of socioeconomic activities e.g. tourism, fishing and agricultural activities which are the mainstream of livelihood for many people. These activities have partly contributed to the increase in the human population in the area surrounding LVB, and have posed a number of challenges to sustainable use of the ecosystem due to overabstraction of water and other resources, loss of biodiversity and pollution of the Lake in Kenya where the study area is located, Uganda and Tanzania. However, on this note little research has been conducted on socioeconomic factors influencing utilization of environmental and fisheries research finding by Fisher folks who depend on the Lake for livelihood. Likewise, the various channels used in dissemination of environmental research findings and its utilization are not clear. Furthermore, the relationship between the fishing effort and BOD, $\mathrm{pH}$, Temperature, Turbidity, number of fishers from 1997 to 2011 is not well documented to create awareness to the fisher folks. This puzzling situation raises a fundamental question as to what might be the reason for the mismatch between available environmental research findings and continuing environmental degradation of LVB. It is against this recognition of this gap that this study sought to determine the influence of socioeconomic factors on utilization research findings in the management of the environment and fisheries by fisher folks in Kisumu Municipality.

\section{Literature Review}

Lake Victoria is one of the Lakes which has benefited from varied number of research with many publications which have been generated (personal communication with Prof Wellington Otieno of Restech Maseno University $23^{\text {rd }}$ August 2013). A lot of the research material which are useful to fisher folks and other researchers who would like to advance research are found all over. They need to be brought in one central place, synthesized and made simple which can be disseminated to the general population to create awareness on various environmental degradations and fisheries challenges taking place within the LVB. Improved utilization of research information to broader groups in society is important for progress and is linked to accountability and sharing of know how. If the vast research findings are properly disseminated to the various fisher folks who will eventually read and understand the findings. They can utilise the findings to implement plans and policies in the management of environmental and fisheries resources sustainably. Promotion of utilization of research findings is also supported by the Lake Victoria initiave through its awareness and sensitization programmes on environmental degradation (www.Uvb.ac.be/klimo ostoolkit /site). Studies by UN-HABITAT, (2008), reveal that several researches have been done which have generated alot of information that can be of assistance to local community in the management of environment. However UN-HABITAT noted most of these findings are not reaching the people who may need them most since the level of awareness of existence of research findings are low and hence they are not using them. The study however did not examine the linkage between socioeconomics factors and utilization of research findings in the management of the social issues affecting the environment as their focus was on promotion of biodiversity in and around Lake Victoria. There was need therefore to examine the influence of socioecominc factors on the application of research findings to solve today to day challenges facing environment which impacts the communities around the lake.

Within Lake Victoria itself the natural resources are used by many fisher folks in different ways to sustain their livelihoods either directly or indirectly. These resources are not used in a sustainable way. Some of the stakeholders within Lake Victoria who are using the resources are; BMU, Fishing communities, Research institutions, Universities, Local Government Authorities, Traders and Factories (FAO, 2006). This article did not go further to explain if the kind of pollution going on within the Lake through discharge of raw untreated sewage effluent, washing of cars right inside the Lake (Sitoki et al., 2013), was as a result of lack of knowledge and awareness among stakeholder on how they are affecting the Lake's ecosystem or they are aware of 
ecosystem health information and they have chosen to ignore it since it's a source of livelihood. From this information all the stakeholders need to be engaged through the use of existing research findings on how to restore the Lake ecosystem and use it in a sustainable way. This study seeked to establish the missing links between socioeconomic factors and utilization of research finding for sustainable management of this resource. The findings of this research brought out socioeconomic factors which influenced utilization of research findings for management of the environment and fisheries sustainably.

With the changing aquatic environment due to nutrients enrichment and competition for oxygen, the fish stock has been on the decline, fish diversity has also been on the decline, the end result has been income generating activities which heavily relies on fishing industry has also been affected (UN-HABITAT, 2008; Nation correspondent, 2014 October $7^{\text {th }}$ ). That means less earnings from fishing, recreational activities, business which used to thrive have ended up being abandoned and neglected as people move to other business ventures. This has led to lowering the socioeconomic status and standard of living in these areas which might be associated with high incidence and spread of HIV/AIDS (Vincent et al., 2009; UN-HABITAT, 2008). This problem of low standards of living is not only affecting the surrounding of Dunga Beach, Paga and Usoma but it's also affecting the shore which surrounds Lake Victoria. This study did not go further to establish if their is a link between socioeconomic factor and utilization of research findings for management of environment and fisheries. In this situation where the LVB ecosystem has been degraded, fisher folks need to utilise the various environmental and fisheries research finding through created awareness to draw a link between the various socioeconomic activities they are carrying out and its effects on the LVB. This is where this research came in to establish the influence of socioeconomic factors on utilization of environmental and fisheries research findings.

The other problem which has been experienced within LVB, is high losses which are as a result of post-harvesting fish due to poor handling techniques and facilities which are lacking and if they are present they are wanting (Eric et al., 2004). The fisher folks ended up losing so much in terms of revenue and fish being rejected in other markets locally and internationally (Eric et al., 2004). This ends up pushing the fisherfolks to extreme poverty.

Related research has been done on the influence of socioeconomic factors on utilization of research for sustainable development focusing on the impact of functional literacy on lives of beneficiaries in Agona district, Ghana. The result of this study established a relationship between socioeconomic lives of the beneficiaries participation and the improvement in functional literacy classes (Arko et al., 2009). The result showed that beneficiaries of the functional literacy classes could read, write and do numerical calculations to some appreciable extent which help them in trading activities. Furthermore it was found that beneficiaries of the literacy classes had become conscious of the need to improve upon their health status Arko et al. (2009). However what this research did not address was to relate the influence of socioeconomic factors on utilization of various generated researches for sustainable use of the resources they have. This research established the influence of socioeconomic factors on utilization of environmental and fisheries research finding generated.

Another related research though in the field of Medicine which represent the same concept, was done by Estabrooks et al., (2007). It determined independent factors that predict research utilization among nurses, taking into account influences of individual nurse, specialty and hospital level. From these research findings it demonstrate that socioeconomic status of individual plays a big part in research utilization Estabrooks et al., (2007). A similar research need to be done within LVB to establish if there was any link between socioeconomic factors and utilization of environmental and fisheries research finding for management of the environment and fishing effort. In conclusion, a gap existed which needed further research on influence of socioeconomic factors on utilization of environment and fisheries research findings. This research focused on socioeconomic factors that influence the utilization of environmental and fisheries research findings.

\section{Research Methodology}

This study was conducted in Kisumu East District which is located on the western region of Kenya in Kisumu county at $34^{0} 42^{\prime} 49^{\prime \prime} \mathrm{E}$ to $34^{\circ} 46^{\prime} 47^{\prime \prime} \mathrm{E}$ and $00^{\circ} 06^{\prime} 144^{\prime} \mathrm{S}$ to $00^{\circ} 01^{\prime} 13^{\prime} \mathrm{S}$. It is one of the three Districts found in Kisumu County namely Kisumu west, Kisumu East and Nyando. Kisumu East District has two divisions Winam and Kadibo. It has twenty locations namely; Kondele, Kolwa Central, Kolwa west, Kolwa East, Kisumu South West, Kisumu Central, Kisumu East, Kisumu North, Kajulu East, Kajulu West, Miwani, Kawino North, Kawino South, West Kochieng, East Kochieng, Komura, Bwanda, Katho and Kanyagwal. The study area falls between at $34^{0} 35^{\prime} 52^{\prime \prime} \mathrm{E}$ to $34^{\circ} 47^{\prime} 22^{\prime \prime} \mathrm{E}$ and $00^{\circ} 09^{\prime} 27^{\prime \prime} \mathrm{S}$ to $00^{\circ} 02^{\prime} 55^{\prime \prime} \mathrm{S}$. The size of Kisumu East District is $559.2 \mathrm{~km}^{2}$ (ROK, 2009). 


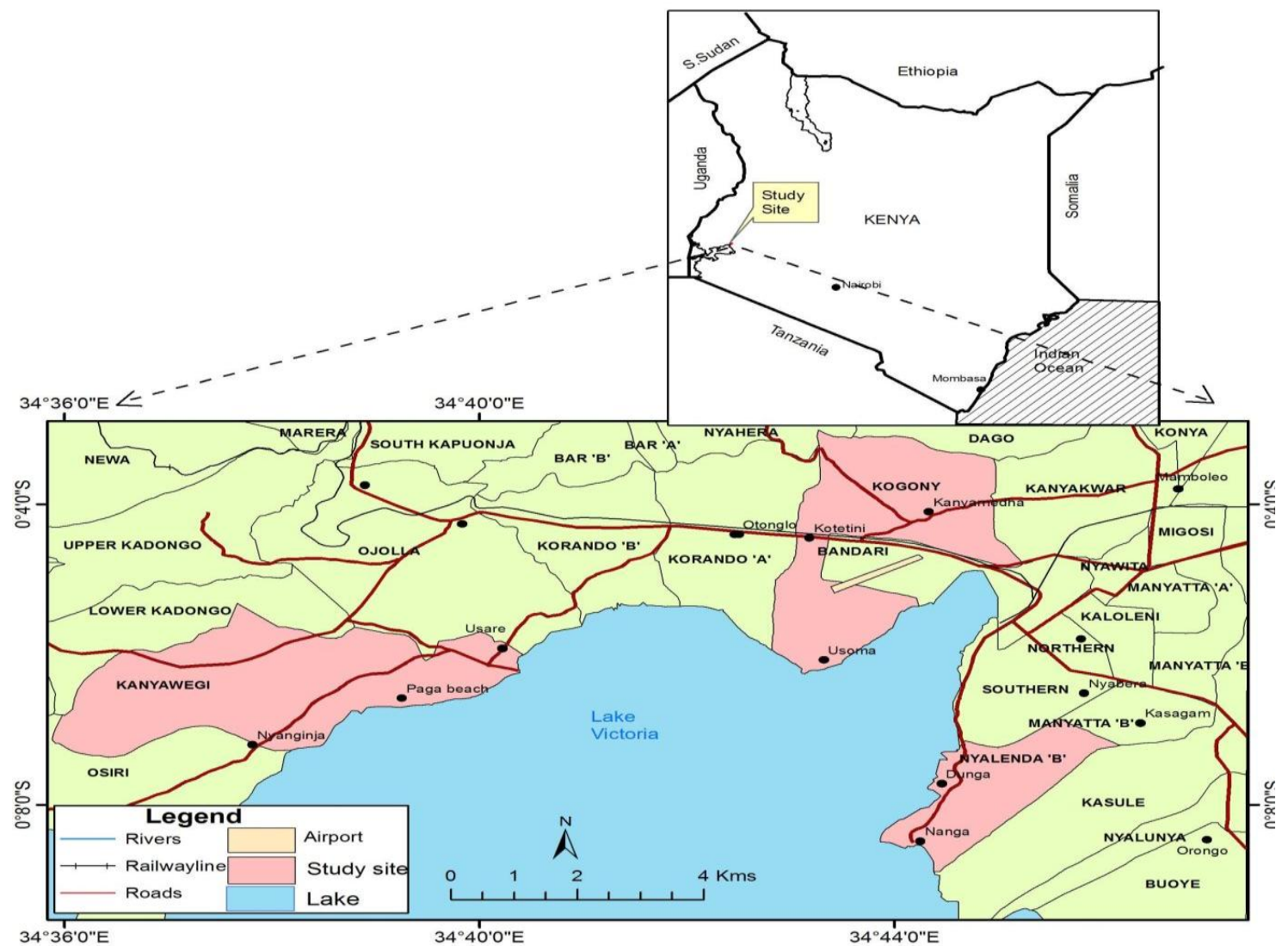

Figure 1: Map of Kenya Showing the study area Kisumu Municipality.

The study adopted a cross-sectional descriptive design. The unit of analysis was the households and the respondents were household heads. From a study population of 15,179 households, a minium sample of 384 household heads were used, proportionate sampling and systematic sampling were used to select households according to location of study area. Purposive sampling was used to sample Key informants who are not fisher folks and are knowledgeable about the situation within LVB. These included one for each group; Fishery officer, Kenya Wildlife Services, Agricultural officers, Area chief, leader of BMU, NGO, CBO and Minister of Fisheries in Kisumu County Government. Questionnaires, interviews, focus group discussion, and observation were used to collect primary data on socioeconomic factors affecting the utilization of environmental and fisheries research findings among the fisherfolks. The quantitative data on the influence of socioeconomic factors on utilization of research findings among the fisher folks was analyzed using descriptive and inferential statistics to generate the percentages, bar graphs and establish relationships between the two variables.

\section{Findings of the Study}

When social economic index of the study area was ranked, it emerged that most respondents $\mathrm{N}=384$ viewed place of worship as the best in ranking with a Mean of 3.28 and standard deviation of 0.82 . This demonstrated that there was less variation among the respondent view. Strangely, when one observes the place of worship in the study area some were located in places which are not clean with leaking sewage lines. The second in ranking was access to electricity was good respondents $\mathrm{N}=385$, mean 2.88 and standard deviation 1.08. This demonstrated there was less variation between those who access electricity and who are not accessing electricity i.e more people are connected to electricity. The third in ranking was education $\mathrm{N}=387$, mean 2.61 and standard deviation 0.75 which means there is less variation between children who access education and those who are not accessing education. The fourth in ranking was access to clean water $\mathrm{N}=387$, mean 2.54 , standard deviation 0.85 . This was not good as it demonstrate there was variation in access in clean water where some had good access to this resource while majority do not have access to clean water. The fifth in ranking was access to housing $\mathrm{N}=384$, mean 2.26 , standard deviation 0.76 slightly above average which mean the majority of the respondent had poor access to proper housing. The sixth and seventh was security and sanitation facilities. This was ranked low as most respondents complain of high rate of insecurity in the study areas. On the other hand most respondents lack proper sanitation facilities and this is evident from toilet facilities available and leaking sewage lines. The lowest in ranking were health facilities and roads. This were evident in the study area 
in Kanyawegi and kogony where most respondents complained health facilities were far and were not properly equipped, no medical Doctors and Nurses. As regards the roads most respondents complain the road network were in poor state and needed repair (Table 1). The low ranking of sanitation facilities concurs with the study done by (Eric et al., 2004) where treatment works in municipality are either inadequate, using old technologies, have aging components or have simply ground to a halt. This has lead to contamination of drinking water sources and hence the outbreak of water born diseases. In another study concern health facilities it states that they have improved 15.8\% from 2012 to 2014 (LVFO Secretariat, 2014) contrary to the findings which ranked health facilities low.

Table 1: Index for socio-economics

\begin{tabular}{|l|c|c|c|}
\hline Indicators & $\mathbf{N}$ & Mean & Std. Deviation \\
\hline Rate of access to Electricity & 385 & 2.88 & 1.08 \\
\hline Clean water & 387 & 2.54 & 0.85 \\
\hline Sanitation facilities & 387 & 2.04 & 0.92 \\
\hline Education & 387 & 2.61 & 0.75 \\
\hline Roads & 387 & 1.63 & 0.89 \\
\hline Housing & 384 & 2.26 & 0.76 \\
\hline Health facilities & 386 & 1.86 & 0.95 \\
\hline Security & 383 & 2.15 & 0.97 \\
\hline Places of worship & 385 & 3.28 & 0.82 \\
\hline Social economic factors index & $\mathbf{3 8 8}$ & $\mathbf{2 . 3 5}$ & $\mathbf{0 . 4 7}$ \\
\hline
\end{tabular}

When the respondents $\mathrm{N}=229$ were asked to estimate the monthly income; the mean monthly income was $17,822.27 /=$ from the Business activities and Std Deviation of 23,042.15/=. This demonstrated the income was very low and again it demonstrated it had variations. Since this were the majority, it painted a picture of rampant poverty. For those employed N=64 had mean monthly income of 20,843.75/= with slight Std Deviation of 20016.83/=. This was replicated in estimated average monthly income from farming, investment and other sources of income. In general N=325 mean was $4537.57 /=$ Std Deviation 5957/= this was very low and paint a picture of poverty in the study area (Table 2). This income could not meet the basic need of the respondents. This is in agreement with (Violet and Atieno, 2011) where the majority of the poor earn about USD \$1 per day.

Table 2: Estimated monthly income

\begin{tabular}{|c|c|c|c|}
\hline & $\mathrm{N}$ & Mean & Std. Deviation \\
\hline Estimated average monthly income from business & 229 & 17822.27 & 23042.146 \\
\hline Estimated average monthly income from employment & 64 & 20843.75 & 20016.833 \\
\hline Estimated average monthly income from farming (crops \& livestock) & 72 & 17054.86 & 16188.474 \\
\hline Estimated average income from investment (rent, shares) & 17 & 19794.12 & 18011.332 \\
\hline Estimated monthly income from others & 42 & 9376.19 & 8148.913 \\
\hline Estimated mean monthly income & 325 & 4537.5692 & 5959.19348 \\
\hline
\end{tabular}

Going further as explained in this study about $47 \%$ of the respondents had access to research finds and the remaining 53\% had no access. Of those who had access to research findings the researcher wanted to establish how they were utilizing the research findings to solve the environmental and fisheries problem. From the data (Table 3), to control water pollution $64.4 \%$ of the respondents $\mathrm{N}=185$ occasionally, rarely or never used research finding to solve the problem. This probably explains why the problem of pollution still persists around the study area and by extension affects other areas within the lake region. The same trend replicated itself in chemicals used in farming activities, control of pest using pesticides, construction of toilets, development of policies and development of environmental awareness and campaigns. However $65.7 \%$ of the respondents $\mathrm{N}=181$ used the research findings to ensure the water quality is good. The same trend was observed in the disposal of refuse where $50 \%$ of the respondents $\mathrm{N}=183$ were using research finding to solve the problem. This demonstrates the respondents had a big concern about the disposal of waste in the study area and by extension the whole of Kisumu Municipality. In this situation it can be interpreted the county Government is not doing enough to solve the problem of waste disposal as demonstrated by what is going on in Kachok dumpsite and that probably explain why the respondents are using research findings to solve the problem. As for the fisheries problem facing the lake the majority of the respondents were not using the research findings to solve the problem. For example using the right fishing gears and techniques for fishing, over $70 \%$ of the respondents $\mathrm{N}$ $=157$ occasionally, rarely to never use research findings to solve this problem. The same trend was observed in management of fish breeding grounds, sedimentation of the lake, pollution of the fish habitat, reduction of fish population, extinction of fish species, over fishing and post harvesting techniques of fish. These findings demonstrate the low usage of research findings to solve the fisheries problem affecting the lake and this might probably explain why the fish is decreasing in the lake. At the same time the lake is getting more and more polluted. This concurs with the study by (Joyce et al., 2009) where they stated that informing and educating 
fishing communities on the danger of illegal fishing was considered to be an option for controlling fishing efforts and it was felt that these actions have led to reduction of illegal fishing and reduction in the catching of undersize fish.

Table 3: Frequency of utilization of Research findings

\begin{tabular}{|c|c|c|c|c|c|c|}
\hline \multirow[t]{2}{*}{ STATEMENT } & & \multicolumn{5}{|c|}{ Responses Percentage } \\
\hline & $\mathbf{N}$ & VF & FR & OC & $\mathbf{R A}$ & NE \\
\hline \multicolumn{7}{|l|}{ ENVIRONMENT } \\
\hline Control of Water pollution through oil spillages & 185 & 8.6 & 27.0 & 27.0 & 14.7 & 22.7 \\
\hline Chemicals used in farming activities e.g. fertilizers & 186 & 3.8 & 16.7 & 31.7 & 28.0 & 19.9 \\
\hline Control of pest using pesticides & 185 & 4.3 & 20.5 & 36.2 & 23.2 & 15.7 \\
\hline Disposal of refuse & 183 & 25.1 & 26.8 & 22.4 & 13.7 & 12.0 \\
\hline Ensuring water quality is good & 181 & 18.2 & 29.3 & 18.2 & 21.0 & 13.3 \\
\hline Construction of toilet facilities & 185 & 11.4 & 23.8 & 34.1 & 20.0 & 10.8 \\
\hline Development of policies and practices that protect the environment & 183 & 3.3 & 16.4 & 29.0 & 26.2 & 25.1 \\
\hline Development of environmental awareness campaigns & 183 & 4.4 & 12.6 & 29.0 & 25.7 & 28.4 \\
\hline \multicolumn{7}{|l|}{ FISHERIES } \\
\hline Use of fishing gears and techniques & 157 & 7.6 & 19.1 & 24.2 & 22.3 & 26.8 \\
\hline Management of fish breeding grounds & 154 & 3.2 & 19.5 & 25.3 & 23.4 & 28.6 \\
\hline Sedimentation of the Lake & 154 & 1.3 & 15.6 & 27.9 & 22.1 & 33.1 \\
\hline Pollution of fish habitat & 154 & 7.1 & 19.5 & 23.4 & 27.9 & 22.1 \\
\hline Reduction of fish population & 154 & 5.8 & 16.2 & 32.5 & 24.0 & 21.4 \\
\hline Extinction of fish species & 153 & 7.8 & 13.7 & 25.5 & 28.1 & 24.8 \\
\hline Over fishing & 153 & 11.1 & 13.7 & 17.0 & 26.8 & 31.4 \\
\hline Post harvest facilities/techniques & 142 & 12.7 & 16.2 & 14.1 & 21.8 & 35.2 \\
\hline
\end{tabular}

Key: VF=Very Frequent, FR=Frequent, OC=Ocationally, RA= Rarely, NE=Never

When the utilization of research findings environmental index was calculated, the findings demonstrated a big variation in the utilization of research findings to solve the environmental problem. The majority of the respondents do not use the research findings. Going by the ranking the majority of the respondents $\mathrm{N}=183$, mean 3.39 and standard deviation 1.32 use the research findings to solve the problem of refuse disposal, however there exist a big variation between those use research findings and those who do not use it. This was followed closely by those who use research findings to ensure the water quality is good. Again in this situation, a big variation exists between those who use research findings and those who do not use. This was replicated in construction of toilet facilities, control of water pollution through oil spillages, control of pest using pesticides, chemicals used in farming activities, development of policies and practices that protect the environment and lastly, development of environmental awareness campaign (Table 4). In general, the results demonstrate research findings are not used to solve the environmental problem. This probably explain why the environment continue to be degraded and this concurs with studies by (Ochola, 2006) who stated that key land degradation issues included escalated soil erosion, agro-chemical pollution, salination and los of land cover.

Table 4: Research findings environment index

\begin{tabular}{|l|c|c|c|}
\hline Statement & $\mathbf{N}$ & Mean & SD \\
\hline Control of Water pollution through oil spillages & 185 & 2.84 & 1.29 \\
\hline Chemicals used in farming activities e.g. fertilizers & 186 & 2.56 & 1.10 \\
\hline Control of pest using pesticides & 185 & 2.75 & 1.09 \\
\hline Disposal of refuse & 183 & 3.39 & 1.32 \\
\hline Ensuring water quality is good & 181 & 3.18 & 1.32 \\
\hline Construction of toilet facilities & 185 & 3.05 & 1.15 \\
\hline Development of policies and practices that protect the environment & 183 & 2.46 & 1.13 \\
\hline Development of environmental awareness campaigns & 183 & 2.39 & 1.15 \\
\hline Utilization of research findings environment index & $\mathbf{1 8 6}$ & $\mathbf{2 . 8 0}$ & $\mathbf{0 . 7 4}$ \\
\hline
\end{tabular}

When the utilization of fisheries research findings index (Table 5) below was calculated for all the respondents in the study area, pollution of the fish habitat ranked highly $\mathrm{N}=154$, Mean 2.62 and Standard Deviation 1.23. This was followed by reduction of fish population $\mathrm{N}=154$, Mean 2.61 and Standard Deviation 1.16. The third in ranking was use of fishing gears and techniques $\mathrm{N}=157$, Mean 2.59 and Standard Deviation 1.28. The fourth in ranking was extinction of fish species in the lake $\mathrm{N}=153$, mean 2.52 and Standard Deviation 1.23. The fifth in ranking was post harvesting facilities/techniques of handling fish $\mathrm{N}=142$, Mean 2.49 and Standard Deviation 1.43. The sixth in ranking was overfishing N=153, Mean 2.46 and Standard Deviation 1.35. The seventh in ranking was management of fish breeding grounds $\mathrm{N}=154$, Mean 2.45 and Standard Deviation 1.19. The last in ranking was sedimentation of the lake $\mathrm{N}=154$, Mean 2.30 and Standard Deviation 1.13. This data which was analysed point to a situation where the general population who access the research findings on fisheries tend to use it to understand/solve the pollution problem and the fish population decrease in the lake. 
This was followed closely by use of fishing gears in the lake. Generally, there was big variation between those who use research findings on fisheries and those who were not using it. These findings points to a situation of lack of awareness among the general population. The findings also probably explain why the lake is polluted and the fish population is on decrease. When the data was analysed deeper and specifically among the fishers themselves the highest in ranking was the use of fishing gears and techniques N=53, Mean 2.89 and Standard Deviation 1.25. This was followed by reduction of fish population in the lake $\mathrm{N}=52$, Mean 2.87 and Standard Deviation 1.24. The third in ranking was pollution of the fish habitat N=50, Mean 2.76 and Standard Deviation 1.24. This findings demonstrate that the fishers who have access to fisheries research findings use it to solve the problem of fishing gears and techniques, reduction of fish population and pollution of the lake. While at the same time there is a group of fishers out there who have no access to fisheries research findings to solve the fisheries problem. This probably explains why the lake is polluted and the fish is decreasing. This is not auguring well for the future of the lake. This concurs with FGD in Dunga, Paga and Usoma beach who mention during discussion that they don't get fisheries research findings to know what is affecting the lake, but they know very well the fish in the lake is decreasing and they think it is because the lake is being polluted from many sources. Most of the participants admitted that they are using fishing gears which are not appropriate for fishing and are aware that they are even catching young fish which have not fully grown. This is not their wish but they are driven by poverty to get any fish from the lake so long as it can put food on the table. They argue they have no other source of livelihood and the lake is what they depend on. During the FGD in Usoma one of the participants accused the National Government of not taking good care of the lake because it is in opposition zone and it is a scheme to make them poor. The question he asked why is the National Government putting more resources in developing Tea sector, Coffee sector and development of Aquiculture/fish farming in central Kenya and not doing the same in Lake Victoria which produce fish which is even exported? Strangely another participant asked why are more processing factories in Thika town than in Kisumu? And why are there no cold room facilities around the lake to help the fishers? According to him this was economic sabotage by the Government of the day. Another asked why is the Government reluctant to take action against those who are polluting the lake such as Matchbox plant, Molases plant in Kisumu and Muhoroni agrochemical plants? His answer was simple corruption is involved and nobody cares about the state of the lake and the fishers.

Table 5: Utilization of fisheries research findings index

\begin{tabular}{|c|c|c|c|c|c|c|}
\hline \multirow[t]{2}{*}{ Statement } & \multicolumn{3}{|c|}{ Fisherpersons } & \multicolumn{3}{|c|}{ All persons } \\
\hline & $\mathbf{N}$ & Mean & SD & $\mathbf{N}$ & Mean & SD \\
\hline Use of fishing gears and techniques & 53 & $2.89 *$ & 1.25 & 157 & 2.59 & 1.28 \\
\hline Management of fish breeding grounds & 51 & 2.55 & 1.17 & 154 & 2.45 & 1.19 \\
\hline Sedimentation of the Lake & 52 & 2.5 & 1.21 & 154 & 2.3 & 1.13 \\
\hline Pollution of fish habitat & 50 & $2.76^{*}$ & 1.24 & 154 & $2.62 *$ & 1.23 \\
\hline Reduction of fish population & 52 & $2.87 *$ & 1.24 & 154 & $2.61 *$ & 1.16 \\
\hline Extinction of fish species & 49 & 2.49 & 1.37 & 153 & 2.52 & 1.23 \\
\hline Over fishing & 52 & 2.56 & 1.35 & 153 & 2.46 & 1.35 \\
\hline Postharvest facilities/techniques & 49 & 2.27 & 1.32 & 142 & 2.49 & 1.43 \\
\hline Utilization of research findings fisheries index & 53 & 2.51 & 0.88 & 158 & 2.42 & 0.89 \\
\hline
\end{tabular}

As a result of the above findings simple linear regression analysis was used to determine the influence of socioeconomic status on utilization of research findings. The respondents' socio-economic index was regressed on that of utilization of research findings during the analysis. The results of the regression test are in (Table 6).

Table 6: Regression Test

\begin{tabular}{|l|c|c|c|c|c|}
\hline Model & \multicolumn{2}{|c|}{ Unstandardized Coefficients } & Standardized Coefficients & t-value & \multirow{2}{*}{-value } \\
\hline & B & Std. Error & Beta & & \\
\hline (Constant) & 1.792 & 0.259 & & 6.932 & .000 \\
\hline Socio-economic factor & 0.410 & 0.110 & .320 & 3.741 & .000 \\
\hline
\end{tabular}

$\mathrm{r}=.320, \mathrm{R}^{2}=.102, \mathrm{R}^{2}$ Adjusted $=.095, \mathrm{~F}(1,123)=13.992, \mathrm{p}>.05$

The regression output in Table 6 show that the relationship between the fisher folks socio-economic status and utilization of research findings was positive $(\mathrm{r}=.320)$. The results further show that socio-economic status accounted for $10.2 \%\left(\mathrm{R}^{2}=.102\right)$ of the variation in utilization of research findings. The beta coefficient $(\beta$ $=.320, \mathrm{p}>.05)$ show that socio-economic status significantly influences utilization of research findings.

\subsection{Summary of the Findings of the Study}

In summary, the study found that Fisher folks socioeconomic status in the study area significantly influence the utilization of research findings for the management environment and fisheries $\mathrm{R}^{2}=0.102, \beta=0.32$, $\mathrm{p}>0.05$. 


\section{Conclusion}

Analysis of social economic activities and utilization of research findings for the managementof environment and fisheries depicted a relationship existed between social economic activities and utilization of research findings. The findings demonstrated that social economic activities do influence the utilization of research findings.

\section{Recommmendation}

The Kisumu Municipality/County Government should take a deliberate step to reduce poverty levels by creating a conducive alternative investment opportunies to reduce over dependancy on the lake as source of employment.

\section{References}

[1]. David, D., Angela, H. A., Mark, O. G, Zen-Ichiro, K., Duncan, J. K., Christian, L., Robert, J. N., Ann-Helene, P. R., Doris, S., Melanie, L.J. S., Caroline, A. S., (2006). Fresh Water Biodiversity: Importance, threats, status and conservation challenges. Cambridge Philosophical Society 81: 163-182.

[2]. Eric, O. O., Daniel, O, O., Kassim, K., Micheni, N., Shem, W., (2004). Mitigation of Environmental Problems in Lake Victoria, East Africa: causal chain and policy option analysis. Royal Swedish academy of science Ambio Vol. 33 No 1-2.

[3]. FAO., (2006). Lake Victoria Fisheries Organization and FAO National Stakeholder's Workshops on Fishing Efforts and capacity on Lake Vctoria. FAO Fisheries and Aquaculture Report No. 817 Rome, FAO 2008. 79p.

[4]. Goteborg University., (2007). Environmental Policy Brief for Lake Victoria Basin.www. Uvb.ac.be/klimonstoolkit/site. 1/4/2014. 2:50pm.

[5]. Johnson, T.C., Kelts, K., Odada, E., (2000). The Holocene History of Lake Victoria. Ambio29 : 2-11.

[6]. Joyce, K., Carol, T. K., Timothy. O., Angelous, T. M., (2009)., Management of Fishing capacity in Nile perch fisheries of Lake Victoria. African journal of Tropical Hydrobiology and Fisheries.

[7]. Linda, M. C., Robert, E. H., Joseph, N., Rose, M., George, D. D., (2003).Distribution and Food-Web Transfer of Mercury in Napoleon and Winam Gulfs, Lake Victoria, East Africa. Journal of Great Lake Research 29(2): 267-282.

[8]. LVFO Secretariat, (2014)., Regional status report on lake victoria Bi-ennial frame survey between 2000 and 2004 . Regional frame survey report.

[9]. Nation correspondent., (2014, October $\left.7^{\text {th }}\right)$. Risk of War as Nile Treaty Delays. Daily Nation Page 9.

[10]. Novine, E. D., Robert, E. H., Timothy, B. J., Jouko, S., John, M. D., Maiju, L., Lars, G. R., Charles, P. M., Fran, W., (2010). Metric of Ecosystem status for large aquatic systems.A global comparison.Joural of Great Lakes Research 36: 123-138.

[11]. Ochola, W.O., (2006). Land cover, land use change and related issues in lake victoria basin: states,drivers, future trends and impact on environment and human livelihood. United Nation Environment Program.

[12]. Regional Frame Survey Report, (2012).Regional Status Report on Lake Victoria Biennial Frame survey between 2000 and 2012 Kenya, Tanzania and Uganda.

[13]. RoK., (2009). Kenya population and Housing Census. Kenya government printing press.

[14]. Sitoki, L., Werner, K., Eugen, R., (2013). Planktonic needle-shaped Nitzschia species from Lake Victoria, Africa, revisited. Diatom Research, 28:2, 165-174.

[15]. Stephen, R.C., Emily, H. S., Zanden, J. V., (2011). State of the world's Fresh water ecosystems: Physical, Chemical and Biological changes. Annu. Rev. Enviro. Resource. 36: 75-99.

[16]. Un-habitat, (2008). Promoting Bidiversity I and around the Lake Victoria Basin. United Nation.

[17]. Violet, M., Atieno, N., (2011). The Lake Victoria initiative. Ten years of Sweden-EAC partnership. Embassy of Sweden Nairobi.

[18]. Vincent, O, O., Joyce, I, N., Radhmina, M., (2009). Implementing co-management of Lake Victoria Fisheries: Achievement and challenges. African journal of Tropical Hydrobiology and Fisheries $12: 52-58$.

[19]. Wolfgang, J. J., Shuguing, A., Finlay, C. M., Brij, G., Jan, K., Stephen, A. M., Wiliam, J. M., Richard, D. R., (2013). Current state of knowledge regarding the world's wetlands and their future under global climate change: A synthesis.

[20]. World Bank, (2009). LVEMP II Project Appraisal Document Report No. 45313 AFR 197 pp 